\title{
Remote education and its effects on peripheral areas - summary of Polish research findings in the project "Preventing post-COVID Social Exclusion Together"
}

Most of the research on remote education was carried out using the online survey methodology (CAWI). Therefore, the obtained knowledge comes mainly from middle-class youth who have full access to the Internet and who are more motivated to complete online surveys.

However, greater problems with remote education may have been experienced by students located outside large cities, in rural areas constituting the socio-economic periphery.

Therefore, a study was carried out to determine what remote education looked like among students living in peripheral areas, the first study of this type in Poland, in the so-called "Local Poland". An example of such peripheries is the Strzyżów poviat in the Podkarpackie voivodship. It was deliberately selected because it obtained the lowest values of socio-economic development indicators in the entire Podkarpackie region.

In selected primary schools in the poviat, a questionnaire was carried out using the auditorium technique, where paper questionnaires were distributed to students in which they marked their answers. Thanks to the use of this methodology, all present students in grades 7 and 8 were included in the study. The study was carried out on November 25-30, 2021. A total of 552 students were surveyed. The research was carried out at the end of the third month of in-school education after a pandemic caused break from stationary education which lasted for more than a year.

The conducted research on students from 4 countries (Poland, the Czech Republic, Slovakia and Hungary) is part of the project Preventing post-COVID Social Exclusion Together (Strategic Grant No. 22110213) that is co-financed by the Governments of Czechia, Hungary, Poland and Slovakia through Visegrad Grants from International Visegrad Fund. The mission of the fund is to advance ideas for sustainable regional cooperation in Central Europe.

The first group of questions was whether young people in rural and peripheral areas had access to online lessons, or whether they were not educationally excluded due to economic, geographic and social conditions.

The obtained results show that $93 \%$ of students have constant Internet access, $93 \%$ have a study desk, $87 \%$ have a private room, $97 \%$ have a smartphone, $64 \%$ have a tablet, $92 \%$ have a laptop, $65 \%$ have a desktop computer, $88 \%$ have a printer, and $44 \%$ have a scanner.

$93 \%$ of students answered yes (including definitely yes - $51 \%$ and yes - $42 \%$ ) to the question whether the equipment and technical condition of their household appliances made it possible to fully participate in online classes. Thus, it can be seen that the vast majority of students in the countryside had access to distance learning. However, it should be emphasized that $7 \%$ of students were excluded from this form of education. 
During online lessons, students mainly used a laptop - 65\%, 22\% used a desktop computer, $10 \%$ used a smartphone, and 3\% used a tablet. This means that the equipment used by the students allowed them to participate effectively in remote lessons.

Most of the students declared that the device they used was their own (80\%), and $17 \%$ shared a device with their siblings. Only a few used a device borrowed from the school (3\%).

The surveyed students most often participated in remote education in their own room (84\%). Some participated in remote education in a room shared with siblings $(10 \%)$ or another room with other household members (like a living room, kitchen) $6 \%$.

Summarizing the conducted analysis of the technical and material base of rural students, it can be stated that every fifth surveyed student could have a problem with access to appropriate conditions enabling full participation in online lessons.

On the one hand, the effectiveness of remote education is determined by the technical accessibility of the Internet and the premises used for learning. On the other hand, pedagogical and environmental factors also influence the outcomes of online learning.

The assessment of the level of classes in comparison to traditional classes was negative. As many as $61 \%$ of students considered that the online lessons were conducted at a lower level than traditional lessons (much lower 20\%, slightly lower $41 \%$ ). For $23 \%$ of students, the lessons were at the same level. The remaining students $(16 \%)$ considered that the lessons were conducted at a higher level. Unfortunately, the main problem of remote education was the educational loss. Students confirm this fact. To the question whether the transition to remote education resulted in a deterioration of their knowledge of school subjects - 39\% of students answered positively, $43 \%$ negatively, and $18 \%$ were unable to take a position.

During remote lessons, students of older grades of primary school (during remote education they were in grades 6 and 7) could encounter a number of different problems that prevented effective education.

Research results show that $12 \%$ of students did not receive any help during online lessons despite needing it, and $15 \%$ of students said they did well and did not need any help. Most of the students needed support during their home education. Most often help was obtained from parents $54 \%$, colleagues $38 \%$, from the Internet (ready solutions) $31 \%$, siblings $26 \%$, other family members (grandparents) $15 \%$, teachers $13 \%$, and tutors $12 \%$.

The research results show that remote education could reduce the effectiveness of pedagogical communication, which in turn leads to educational loss and backlog. As many as $85 \%$ of students used the help of other people during remote education, mainly the help of parents and friends. Every tenth student was left to fend for himself or herself and did not receive help from anyone.

In the discourse on remote education, a lot has been said about the so-called dropping out of online lessons or coronavirus truancy. The matter is difficult to investigate, because students may conceal these unfavorable facts in their assessments. Despite that, we tried to see what the involvement in online lessons looked like.
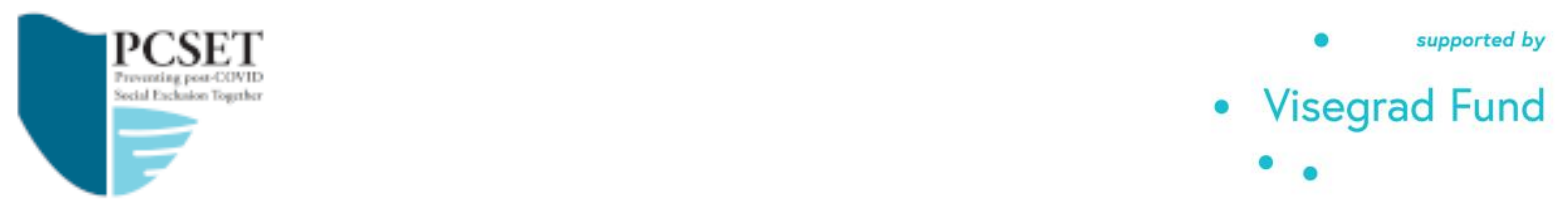
The obtained answers show that $42 \%$ of students participated in all online lessons, $49 \%$ in most lessons, $6 \%$ in some of the lessons, and 2\% did not participate. Again, we can take into account that this fact is concealed by students, which leads to the conclusion that every tenth student was logged out of online lessons.

The main reasons for the lack of participation in online lessons were illness (38\%), lack of appropriate equipment (29\%), other (most students included problems with the computer or the Internet) (26\%), fatigue with remote education (21\%), boring lessons (15\%), failure to cope with online lessons (14\%), the need for help with homework (11\%), taking care of siblings (10\%), lack of interest in education (10\%), skepticism towards remote education (10\%), the need to help on a farm (5\%), caring for sick parents (4\%), and gainful employment (3\%).

We can see that the missed lessons were mainly due to health problems, technical problems and the inconvenience of remote education for such a long time period.

On average, students spent about 6 hours a day on remote education. They spent about 2 hours a day preparing for online lessons. The parents also helped the students in the lessons, and the duration of this help was about half an hour a day.

It is difficult to determine on the basis of the answers obtained whether the students exhausted themselves or not during the online lessons. Rather, the learning time was similar to that spent at a school desk.

The students ambivalently assessed remote education. On the one hand, they pointed to the "benefits" obtained during home education. These are mainly not getting ready for school, more free time $(85 \%)$, more time for the family $(65 \%)$, the possibility of getting enough sleep and not rushing (60\%), being safe and avoiding the risk of contracting Covid-19 (58\%), and a decrease in the number of duties related to science $(51 \%)$.

However, remote education also has negative sides. First of all, there is the awareness of the educational loss expressed in the answer that more can be learned at school than during remote learning, which was given by $51 \%$ of students. There is also the formation of negative habits, e.g. during remote education, students can "cheat" with the help of parents or siblings (51\%). It was also indicated that too much time was spent at a computer (48\%), that it was difficult to focus on what the teachers said (43\%), problems with understanding the material during the lesson (41\%), developing a habit for remote learning and a reluctance to return to school (35\%), feeling of tiredness and exhaustion (33\%), deterioration of contact with peers $(26 \%)$, deterioration of contact with teachers $(23 \%)$, stress during class speeches $(23 \%)$, absenteeism due to illness $(7 \%)$.

Summing up, it should be said that staying away from school for so long meant that the students gained a lot of free time. However, the overall balance is unfavorable and it is dominated by the feeling of lost educational opportunities, the emergence of bad habits, and psychophysical fatigue.

Apart from gaining free time, remote education, if it is to be effective and efficient, is a difficult and demanding process. The following analyzed answers indicate whether the students met the challenges, or if they succumbed to various temptations.
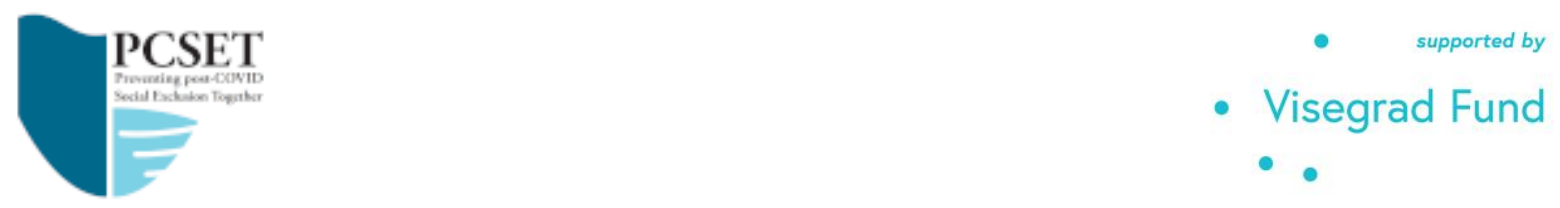
According to students' declarations, $48 \%$ wanted to learn a lot during distance learning. 54\% were convinced that distance learning was interesting. 37\% were looking forward to the online lessons. On the other hand, $28 \%$ could not complete tasks during a remote lesson.

Almost half of the students declared that they participated in online lessons despite the opportunity to do more interesting things (48\%). Tasks and essays were delivered on time by $87 \%$ of students, $44 \%$ managed to focus their attention during classes. $44 \%$ took an active part in school activities. $42 \%$ understood everything that was presented during the online lessons.

It is worth adding that neglecting online lessons has its consequences, which the students seem to be aware of. Among students, 33\% admitted that they had a lot of catching up to do due to distance learning. More than half of the respondents are afraid of the requirements set by teachers (55\%). One third fear that they will not be able to learn at school (33\%).

Summing up, it should be stated that about $50 \%$ of students resisted the temptation and distraction that appeared during the online lessons. About one-third of the students suffered a severe loss of education and could therefore develop school phobia and neurosis.

Unfortunately, the consequences of spending such a long time outside the school environment permanently changed the habits and attitudes of students, which is clearly demonstrated by the answers to the next question.

According to the surveyed students, if they were able to decide on the form of learning themselves, $31 \%$ were in favor of studying at school, $24 \%$ in favor of online learning, $22 \%$ in favor of hybrid learning, $7 \%$ would have stopped learning and $17 \%$ had no opinion.

It is worth emphasizing that the research was carried out in the third month after returning to school and it was clear that the students longed for the lost comfort of remote learning at home. Only a third were satisfied with attending school.

Despite the great turmoil caused by remote education, high educational aspirations still remained. The answers show that after primary school, students will most often continue their education in a general education high school $48 \%$, in a technical school $41 \%$, and rarely in a professional (vocational) school 10\%.

However, the most important discovery among students is their poor mental condition. Earlier assumptions that the youngest did not cope with the pandemic and that the effects of the quarantine would be visible even long after its end were confirmed.

Only $61 \%$ were satisfied with their lives. According to the results obtained using the WHO 5 scale, almost half of the surveyed students (48\%) have depressive moods. The results are surprising as it seemed that meeting peers would allow a return to pre-pandemic "normality".

Summing up the obtained results, it is worth emphasizing that such a low level of mental well-being of students is surprising. We have an epidemic of depression among the older grades of primary school.

Knowledge during remote education was efficiently acquired by about half of the respondents. Every fifth student did not have the technical ability to fully participate in remote lessons. It is worth adding that the long duration of remote learning has created negative habits that
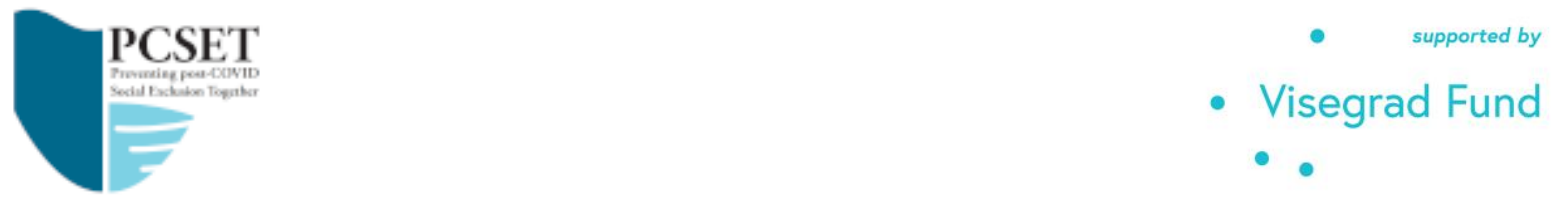
effectively hinder functioning in the post-pandemic reality. Dark scenarios have come true and show that half of the students have serious problems with adapting to the school reality.

The results come from the research carried out as part of the project Preventing post-COVID Social Exclusion Together realized with partners in the Czech Republic, Slovakia and Hungary. The Head of the Research in the project and the contractor of the research on students in Poland is Dr hab. Piotr Długosz, prof. UP. The Polish team also includes Dr. Damian Liszka and Dr. Paweł Walawender. 